\title{
TEM Study of the Morphology Of GaN/SiC (0001) Grown at Various Temperatures by MBE
}

\author{
W.L. Sarney ${ }^{1}$, L. Salamanca-Riba ${ }^{1}$, V. Ramachandran ${ }^{2}$, R.M Feenstra ${ }^{2}$, D.W. Greve ${ }^{3}$ \\ ${ }^{1}$ Dept. of Materials \& Nuclear Engineering, University of Maryland, College Park, MD \\ ${ }^{2}$ Dept. of Physics, ${ }^{3}$ Dept. of Computer \& Electrical Engineering, Carnegie Mellon \\ University, Pittsburgh, PA
}

\begin{abstract}
$\mathrm{GaN}$ films grown on $\mathrm{SiC}(0001)$ by $\mathrm{MBE}$ at various substrate temperatures $\left(600^{\circ}\right.$ $750^{\circ} \mathrm{C}$ ) were characterized by RHEED, STM, x-ray diffraction, AFM and TEM. This work focuses on the TEM analysis of the films' features, such as stacking faults and dislocations, which are related to the substrate temperature. There are several basal plane stacking faults in the form of cubic inclusions for samples grown at low temperatures compared to those grown at high temperatures. The dislocation density is greatest for the film grown at $600^{\circ} \mathrm{C}$, and it steadily decreases with increasing growth temperatures. Despite the presence of various defects, $\mathrm{x}$-ray analysis shows that the $\mathrm{GaN}$ films are of high quality. The double crystal rocking curve full width at half maximum (FWHM) for the GaN (0002) peak is less than 2 arc-minutes for all of the films we measured and it decreases with increasing growth temperature.
\end{abstract}

\section{INTRODUCTION}

$\mathrm{GaN}$ films grown on $\mathrm{SiC}$ usually have high defect densities. Typical defects in $\mathrm{GaN} / \mathrm{SiC}$ films include inversion domain boundaries, stacking faults, and unintended polytype transformations. The presence of these defects emphasizes that even though reducing the lattice mismatch improves film quality, other factors contribute to the nitride film defect morphology [1]. Further defect density reduction may be achieved by enhancing growth conditions. We examine the relationship between the $\mathrm{SiC}(0001)$ substrate temperature and the GaN film quality.

\section{EXPERIMENT}

The damage produced by polishing was removed from Si-face $6 \mathrm{H}-\mathrm{SiC}(0001)$ substrates with ex-situ hydrogen etching [2]. The substrates were then placed into an ultra high vacuum environment (pressure $<10^{-10}$ Torr) and outgassed at about $800^{\circ} \mathrm{C}$ for 30 minutes. In order to replenish any surface $\mathrm{Si}$ that may have been lost during oxide removal, Si was deposited onto the substrate using an electron beam source. Oxide desorption was done by annealing the substrate at about $1000^{\circ} \mathrm{C}$ until a $3 \times 1$ reflection high energy electron diffraction (RHEED) pattern was obtained.

$\mathrm{GaN}$ films were grown by MBE onto the substrates using a Ga effusion cell and a RF-plasma nitrogen source. The growth was a single step process with no nucleation layer growth. We grew four samples with substrate temperatures of $600^{\circ} \mathrm{C}, 650^{\circ} \mathrm{C}, 700^{\circ}$ 
$\mathrm{C}$, and $750^{\circ} \mathrm{C}$. The temperature was monitored using a pyrometer and a thermocouple in contact with the back of the sample mounting stage. Growth was performed under highly Ga-rich conditions relative to the $\mathrm{N}$ concentration [3]. The films were characterized insitu with RHEED and STM and ex-situ with AFM, HRXRD, and TEM. The TEM results were obtained on a JEOL 4000FX microscope operated at $300 \mathrm{kV}$. Cross-sectional TEM samples were prepared using tripod polishing and ion milling at room temperature. Low resolution TEM and a diffraction pattern with two-beam DF conditions were used to examine the defect morphology of the GaN films. HRTEM images and diffraction patterns allow detailed examination of the crystalline structure of the film.

\section{RESULTS \& DISCUSSION}

Figure 1 shows TEM images of the sample grown at $600^{\circ} \mathrm{C}$. The indexed diffraction pattern (Fig. 1a) indicates the presence of the $\mathrm{SiC}$ substrate, the $2 \mathrm{H} \mathrm{GaN}$ film, and some $3 \mathrm{C} \mathrm{GaN}$ regions with zone axes of $(2 \overline{1} \overline{1} 0),(2 \overline{1} \overline{1} 0)$, and $(01 \overline{1})$, respectively. Several of the low index spots from one of the three regions overlap with those from one or both of the other two regions, resulting in some very strong spots. The location of a diffraction spot is related to the lattice spacing. For instance, the small difference in lattice spacing for the $111_{3 \mathrm{C}-\mathrm{GaN}} \operatorname{spot}(\mathrm{d}=0.261 \mathrm{~nm})$, the $0002_{2 \mathrm{H}-\mathrm{GaN}}$ spot $(\mathrm{d}=0.259 \mathrm{~nm})$, and the $0006_{6 \mathrm{H}-\mathrm{SiC}}$ spot $(0.251 \mathrm{~nm})$ results in three spots that cannot be resolved by the TEM, and are labeled as spot 1 in Fig. 1a. Oblong spots (such as spots 2 and 3) are often two very closely neighboring spots. Cubic inclusions are easier to detect when we look at high index spots since the lattice spacing difference is greater. For instance, the $\overline{2} 223 \mathrm{C}-\mathrm{GaN}$ spot (labeled spot 8 in Fig. 1a) is distinguishable from the neighboring $6 \mathrm{H} \mathrm{SiC}$ spot to the right. Spots due to twinning across the (111) plane in the cubic regions and spots due to multiple diffraction between twins or between cubic and hexagonal regions are labeled in Fig. 1a.

Figures $1 \mathrm{~b}-1 \mathrm{c}$ show $(0002)_{2 \mathrm{H}-\mathrm{GaN}}$ and $(01 \overline{1} 0)_{2 \mathrm{H}-\mathrm{GaN}}$ dark field (DF) images of the sample grown at $600^{\circ} \mathrm{C}$. Two beam conditions cause diffraction by specific $h k l$ planes, and result in bright areas in the DF image where the $h k l$ planes meet the Bragg condition [4]. The (0002) $)_{2 \mathrm{~h} \_ \text {GaN }}$ two beam condition is nearly equivalent to the $(111)_{3 \mathrm{C}-\mathrm{GaN}}$ condition, therefore the cubic inclusions do not cause contrast in the $(0002)_{2 \mathrm{H}-\mathrm{GaN}} \mathrm{DF}$ image shown in Fig. 1(b). The vertical defects visible in the (0002) image but invisible in the $(01 \overline{1} 0)$ image are screw dislocations with Burger's vector $\vec{b}=0001$. The vertical defects visible in only the $(01 \overline{1} 0)$ image are edge-type and are probably double positioning boundaries or prismatic stacking faults, as we have observed in other $\mathrm{GaN} / \mathrm{SiC}$ films [5]. Since the $(01 \overline{1} 0)_{2 \mathrm{H}-\mathrm{GaN}}$ two-beam condition does not correspond to a two-beam condition for the cubic inclusions, we expect to see contrast due to the cubic inclusions. There are several horizontal bands in the $(01 \overline{1} 0)_{2 \mathrm{H}-\mathrm{GaN}} \mathrm{DF}$ image (Fig. 1c), which are basal plane stacking faults corresponding to $3 \mathrm{C}-\mathrm{GaN}$ inclusions. High resolution TEM (Figure 1d) shows that the substrate/film interface marked by arrows is high quality and that the initial film nucleated is $2 \mathrm{H} \mathrm{GaN}$.

Diffraction patterns of the films grown at $650^{\circ} \mathrm{C}$ and $700^{\circ} \mathrm{C}$ (not shown here) have the same spots as the pattern for the film grown at $600^{\circ} \mathrm{C}$ (Fig. 1a). There are several regions of cubic $\mathrm{GaN}$ within the $2 \mathrm{H} \mathrm{GaN}$ matrix, as shown in Fig. 2a. The cubic stacking 
in the inclusions and the abruptness of the transition from $2 \mathrm{H}$ to $3 \mathrm{C} \mathrm{GaN}$ is shown in Fig $2 \mathrm{~b}$. The high-resolution image of the sample grown at $700^{\circ} \mathrm{C}$ (not shown here) is very similar to the image of the sample grown at $650^{\circ} \mathrm{C}$, except that it has less $3 \mathrm{C}$ inclusions.

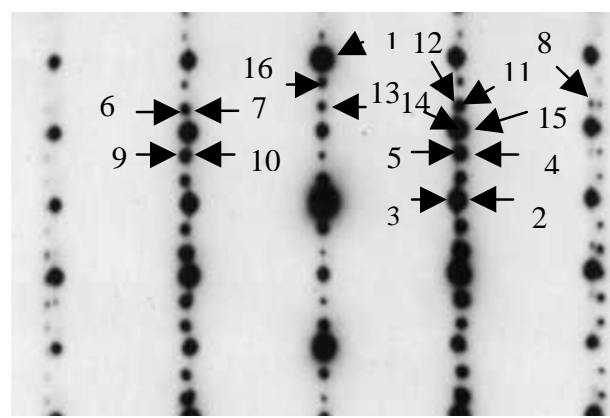

(1a)

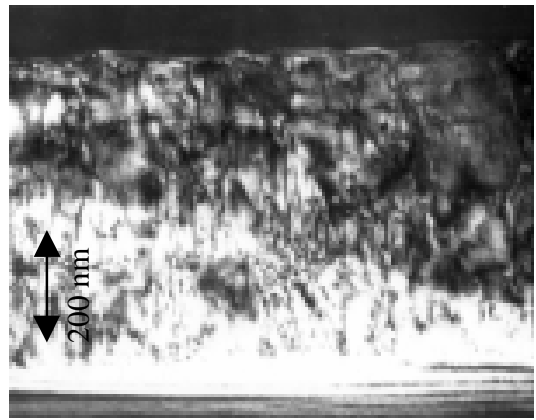

(1b)

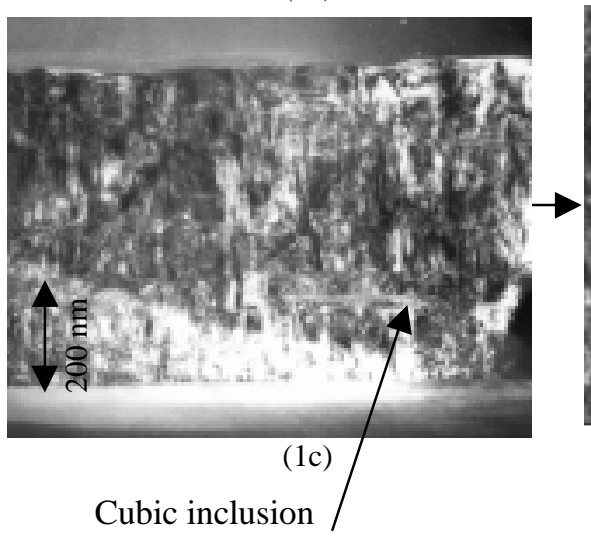

(1) Overlap of $0006_{\mathrm{SiC}}, 0002_{2 \mathrm{H}-\mathrm{GaN}}$, \& $111_{3 \mathrm{C}-\mathrm{GaN}}$ spots, (2) $01 \overline{1} 0_{\mathrm{SiC}}$, (3) $01 \overline{1} 0_{2 \mathrm{H}-\mathrm{GaN}},(4) 01 \overline{1} 2_{\mathrm{SiC}}$ (5) $\overline{1} 11_{3 \mathrm{C}-\mathrm{GaN}},(6) 0 \overline{1} 14_{\mathrm{SiC}},(7)$ $200_{3 \mathrm{C}-\mathrm{GaN} \cdot}$ (8) $\overline{2} 22_{3 \mathrm{C}-\mathrm{GaN}}$, (9) $0 \overline{1} 12_{\mathrm{SiC}},(10)$ Twin of $\overline{1} 11_{3 \mathrm{C}-\mathrm{GaN}}$ spot, (11) $01 \overline{1} 4_{\mathrm{SiC}}$, (12) Twin of $200_{3 \mathrm{C}-\mathrm{GaN}}$ spot, (13) Spot due to multiple diffraction of the $\overline{1} 11_{3 \mathrm{C} \text { - }}$ $\mathrm{GaN}$ spot and its twin across the (111) plane, (14) $01 \overline{1} 3_{6 \mathrm{H}-\mathrm{SiC}}$, (15) $01 \overline{1} 1_{2 \mathrm{H}-\mathrm{GaN}}$, (16) Overlap of $0005_{\text {SiC }}$ spot \& the spot due to multiple diffraction of the $01 \overline{1} 1_{3 \mathrm{C}-}$ $\mathrm{GaN}$ and the $01 \overline{1} 1_{2 \mathrm{H}-\mathrm{GaN}}$ spot.

Fig.1.(a) Diffraction pattern for sample grown at $600^{\circ} \mathrm{C}$, (b) (0002) DF image of the sample grown at $600^{\circ} \mathrm{C}$, (c) $(01 \overline{1} 0) \mathrm{DF}$ image of the sample grown at $600^{\circ} \mathrm{C}$, (d) High resolution image of $\mathrm{GaN} / \mathrm{SiC}$ interface. 


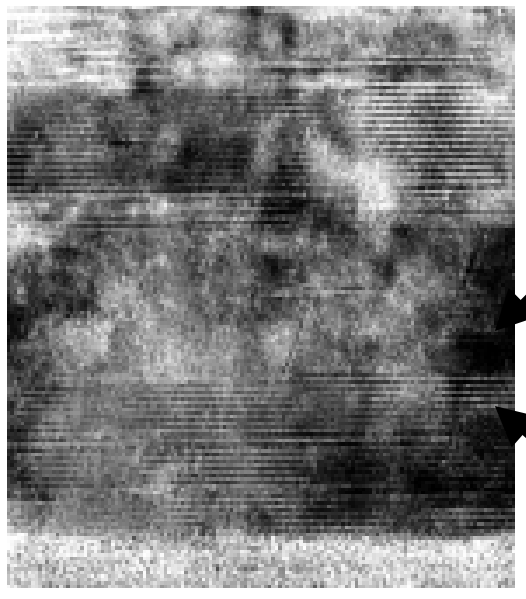

(2a)

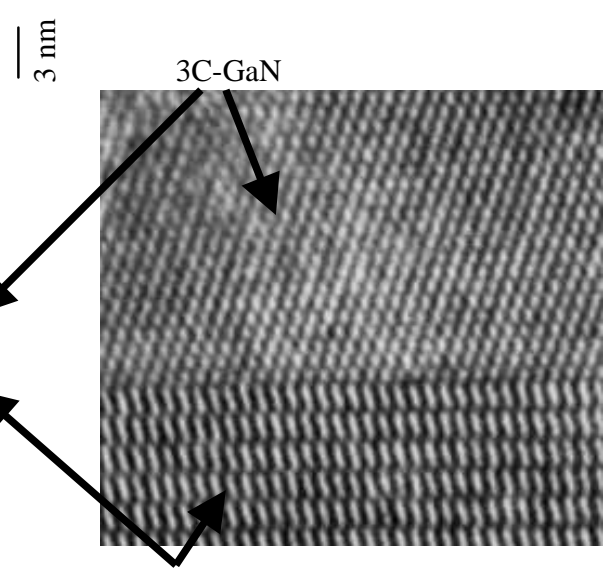

(2b)

$2 \mathrm{H} \mathrm{GaN}$

Fig. 2. (a) High resolution image of sample grown at $650^{\circ}$ C. (b) High resolution image of the interface between a region of $2 \mathrm{H} \mathrm{GaN}$ and $3 \mathrm{C} \mathrm{GaN}$.

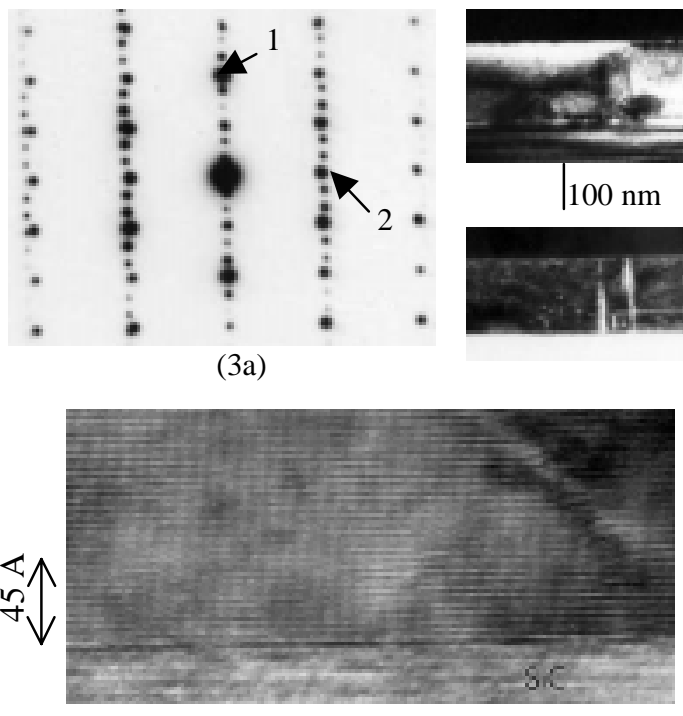

(3d)

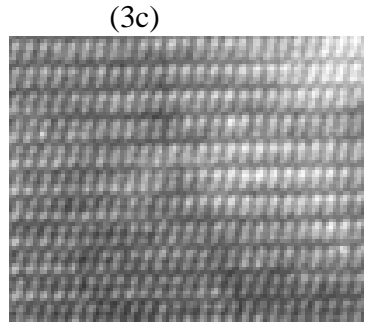

(3e)

Fig. 3. TEM of sample grown at $750^{\circ} \mathrm{C}$. (a) $2 \overline{1} \overline{1} 0_{\mathrm{GaN}} / 2 \overline{1} \overline{1} 0_{\mathrm{SiC}}$ diffraction pattern. Label 1: $0006 \mathrm{SiC}$ and $0002 \mathrm{GaN}$ spots. Label 2: (01 10$) \mathrm{SiC}$ and $(01 \overline{1} 0)$ GaN spots. (b) (0002) DF image and (c) (01 10) DF image (d) High resolution image of $\mathrm{GaN} / \mathrm{SiC}$ interface (e) High magnification image of the $2 \mathrm{H} \mathrm{GaN}$ fringes. 
The film grown at $750^{\circ} \mathrm{C}$ contains very few $3 \mathrm{C}$ inclusions. The $3 \mathrm{C}$ spots are not visible in the diffraction pattern (Fig. 3a) and only a few horizontal bands are seen in the $(01 \overline{1} 0)$ DF image (Fig. 3c). The defect density of this sample is lower than the other three samples, as seen by the reduced number of visible dislocations in the DF images (Figs. 3b \& 3c). High resolution images of the film grown at $750^{\circ} \mathrm{C}$ (Figs. $3 \mathrm{~d}$ and 3e) show that this film is of higher quality the films grown at lower temperatures.

The total dislocation density, the density of threading dislocations which intersect

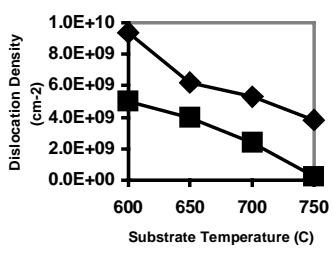

(4a)

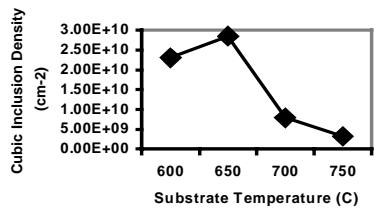

(4b)

Fig. 4. (a) Density of dislocations plotted against substrate temperature. The upper line is the total dislocation density and the lower line is the density of threading dislocations which intersect the surface (b) Density of cubic regions plotted against substrate temperature.

the surface, and the density of cubic inclusions decreases with increasing substrate temperature, as shown in the TEM images and summarized in the Figs $4 \mathrm{a}$ and $4 \mathrm{~b}$. The film grown at $750^{\circ} \mathrm{C}$ has a total dislocation density of approximately $3.2 \times 10^{9} \mathrm{~cm}^{-2}$. The density of threading dislocations which intersect the surface for the film grown at $750^{\circ} \mathrm{C}$ is approximately $2.1 \times 10^{8} \mathrm{~cm}^{-2}$. The threading dislocations which intersect the surface for the film grown at $750^{\circ} \mathrm{C}$ are predominately edge dislocations.

Symmetric triple crystal radial ( $\omega-2 \theta)$ scans (Figs. 5a and 5b) show that the FWHM decreases with increasing growth temperature, except for the film grown at $750^{\circ} \mathrm{C}$. The increase in FWHM for the highest temperature sample is due to the thinness of this sample relative to the other three sample. This sample was grown for the same length of time as the other samples, but the growth temperature of $750^{\circ} \mathrm{C}$ is close to the temperature at which decomposition of $\mathrm{GaN}$ becomes significant (approximately $800^{\circ} \mathrm{C}$ ). Decomposition of GaN during growth reduces the growth rate. The FWHM of the symmetric peak is as low as 30 arcseconds for the films grown at $700^{\circ} \mathrm{C}$. The symmetric peak width is affected by defects which distort the interplanar spacing along the growth
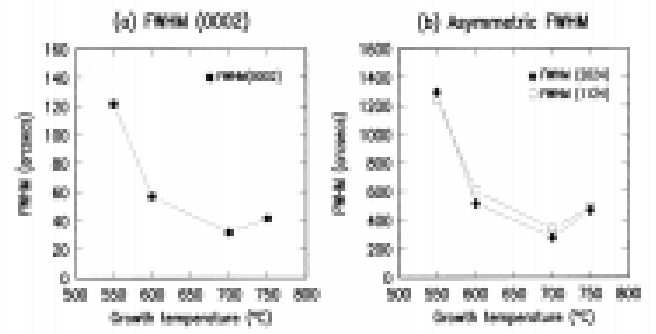

Fig. 5. HRXRD FWHM data for GaN films grown on $6 \mathrm{H}-\mathrm{SiC}(0001)$ as a function of temperature: (a) Symmetric (0002) reflection (triple crystal $\omega-2 \theta$ scans), (b) asymmetric reflections (double crystal $\omega$ scans). 
direction, notably the screw dislocations we see in the DF images. Therefore, the symmetric peak width is unaffected by certain edge dislocations and cubic inclusions $\left(\mathrm{d}_{111-\mathrm{GaN}} \approx \mathrm{d}_{0002-\mathrm{GaN}}\right)$ since they do not distort the interplanar spacing along the growth direction. The asymmetric peak width is a better measure of total dislocation and cubic inclusion densities, which may explain its relatively large width compared to that of the symmetric peak. The x-ray data is discussed more thoroughly elsewhere [6].

Reciprocal space maps around the (0002) reflections show much greater elongation along the $\mathrm{k}_{/ /}$axis for the film grown at $600^{\circ} \mathrm{C}$ than for the film grown at $750^{\circ} \mathrm{C}$. This implies a larger degree of tilt, or mosaicity, in the lower temperature films. Screw dislocations with $\vec{b}=0001$ would cause tilt in a film. These results indicate a decrease in the number of screw dislocations with increasing growth temperature, in agreement with both the TEM and the x-ray results. Furthermore, AFM studies in our previous experiments show a decreasing number of spiral growth fronts with increasing growth temperature [7].

\section{CONCLUSION}

Increasing the growth temperature improves the crystalline quality of $\mathrm{GaN}$ grown on hydrogen-etched $6 \mathrm{H} \mathrm{SiC}$ substrates. TEM shows that defect and cubic inclusion densities significantly decrease as the growth temperature is increased. Furthermore, $x$ ray k-space maps show that the mosaicity of the films decreases sharply with increasing growth temperature. Therefore, we conclude MBE at growth temperatures near the decomposition temperature of $\mathrm{GaN}$ improves the quality of wurtzite $\mathrm{GaN}$ grown on $6 \mathrm{H}$ $\mathrm{SiC}(0001)$.

\section{ACKNOWLEDGMENTS}

The work at Carnegie Mellon was supported by National Science Foundation, grant DMR-9615647, and the Office of Naval Research, grant N00014-96-1-0214.

\section{REFERENCES}

[1] R.F. Davis, T.W. Weeks, M.D. Bremser, S. Tanaka, R.S. Kern, Z. Sitar, K.S. Ailey, W.G. Perry, and C. Wang, Mater.Res.Soc.Symp.Proc. 395, 3 (1996).

[2] V. Ramachandran, M.F. Brady, A.R. Smith, R.M. Feenstra, D.W. Greve, J. Elec. Mat.. 27, 308 (1998).

[3] A.R. Smith, V. Ramachandran, R.M. Feenstra, D.W. Greve, A. Ptak, T.H. Myers, W.L. Sarney, L. Salamanca-Riba, M.-S. Shin, M. Skowronski, MRS Internet J. Nitride Semicond. Res. 3, 12 (1998).

[4] D. Williams \& C. Carter, Transmission Electron Microscopy, Plenum Press, New York: 1996, p. 361.

[5] V. Ramachandran, R.M. Feenstra, W.L. Sarney, L.Salamanca-Riba, J.E. Northrup, L.T. Romano, D.W. Greve, Appl. Phys. Lett. 75, (1999), 808.

[6] V. Ramachandran, R.M. Feenstra, W.L.Sarney, L. Salamanca-Riba, D.W. Greve, submitted to the proceedings of the $46^{\text {th }}$ International Symposium of the American Vacuum Society, to appear in J. Vac. Sci. Technol. A.

[7] V. Ramachandran, A.R. Smith, R.M. Feenstra, and D.W. Greve, J. Vac. Sci. Technol. A. 17, 1289 (1999). 